Article

\title{
The Moral Economy of Micro-Transactions in Digital Games
}

$\$$ sciendo 


\section{ABSTRACT}

In the digital game industry, micro-transactions (MTXs) have been introduced as a new vehicle for profit generation. MTXs are small sum payments for additional virtual content beyond the content players obtain through gameplay and progression, which impose new structural limitations and opportunities for game participation on the players. This article explores the perspectives of players on corporate commodification strategies of gameplay. The empirical work consists of semi-structured focus group interviews of players and interviews of podcast hosts. All informants are players of various online games.

By adopting Sayer's (2004, 2007, 2017) concept of moral economy and de Certeau's (2011) concept of tactics in everyday life, this study draws two conclusions. First, virtual items and goods obtained through in-game activities or MTXs are a means to communicate skill level, taste, and experience between players as a fundamental part of the moral economy of establishing fair ground for competition. With regard to MTXs, players distinguish among three levels in which agency is maintained or limited. Second, players negotiate these models of commodification and agency limitation in ambivalent ways, both resisting and embracing economic values in the moral economy of play. Furthermore, because of this negotiation, players are generally concerned about the invasive nature of economic values taking priority over the values that guide the practices of play. In other words, there is a moral concern regarding how norms and values in play are compromised or overridden by outside economic pressures. 


\section{INTRODUCTION}

In recent years, a range of digital game studios making content for computers, consoles, and smartphones have been adopting new economic models to private value from gameplay. Whereas game companies have traditionally generated income through sales of hard copies of a product (also called premium games) along with merchandise related to the game, the gaming economy includes the initial purchase cost of a game itself followed by an ongoing incentive for purchasing downloadable content if the player wishes to experience the complete game/product.

In this context, the game industry has been introducing even newer economic vehicles for profit generation, so-called loot boxes and micro-transactions (MTXs). MTXs refers to the action of purchasing cosmetic additions or changes to the original design or functional upgrades, which the player can purchase with real money in an in-game store or through a supported publisher store application, which varies depending on the hardware (PC, console, mobile). The additions or changes to the design include virtual cosmetic goods for the player's avatar or other objects of projective identity (Gee 2003). Functional upgrades are game extensions or additional features that are made available to the player upon purchase (Tomić 2018). For example, season passes enables the player to obtain extra rewards through gameplay in PC and console games, or the player can remove advertisements in free-to-play mobile games. The economy of MTXs is based on the notion that players can purchase virtual goods for small sums in order to gain status in a game. For clarity, when referring to MTXs throughout this paper, I mean the items that are purchased rather than the action of purchasing them.

The introduction of the MTX variant - the so-called loot box - has caused particular outrage among players, who view it as a predatory business practice that exploits individuals with a tendency to develop an addiction for gambling (Knaus 2017). A loot box is a virtual box of unknown content. Upon purchase, the player can open the box and receive content of varying "quality". Often, this content is cosmetic and in some cases offers improvements to gameplay. For the players, the loot box MTX provides an additional entry point of engagement with their favourite game(s), if they wish, while players who just want to play the game can freely do so. However, in some cases, publishers permit MTXs to work as gateways for accessing otherwise exclusive game content. In other words, if the players do not purchase these gateway MTXs, they cannot access certain parts of the game. This is problematic for players if such MTXs exist in games for which they have already paid (not free-to-play).

In some cases, it has been argued that loot boxes represent a new form of gambling, causing concerns among regulators, especially when considering play by children (Knaus 2017). This has led to an investigation by one US and 15 European gambling regulators from the Gambling Regulators European Forum, who set out to examine whether loot boxes can be classified as gambling (GREF 2019). In other cases, players have equated the use of MTXs to cheating, condemning it as incompatible with the values and ethics of play.

Hence, while MTXs generally extend earlier practices of trading virtual goods for real money that date back to at least the 1990s (Hamari, Lehdonvirta 2010), their current implementations have made them into a contested object by players and regulators alike. Additionally, MTXs present themselves in so many and varied ways at the same time, that player perception of them is equally varied and dispersed, for example free-to-play mobile games are fundamentally different from conventional $\mathrm{PC}$ or console games that often require a premium purchase before playing. Likewise, even within those games, there are exam-

1 The quality of micro-transactions in video games is determined by their cost as well as their frequency of appearing in loot boxes. This has nothing to do with the data size or its developmental requirements on the production side. Instead, it is an artificial quality and scarcity (cf. Castronova 2006) label (often by color) that lays the foundation for the loot box system. 
ples of free-to-play, free-to-start, and payto-win games. For instance, there is a competitive edge on competitive card games like Hearthstone (Blizzard) for those who are willing to pay for new decks. Likewise, mobile education games like Duolingo could be considered free-to-start in that you have a limited amount of "errors" you can commit before you must wait for your "hearts" to replenish (which takes about 4 or so hours per error); if you wish to continue playing, then you must either wait or pay virtual currency or real-world currency (real-world currency will unlock additional features).

Due to the empirical sample this research generally represents competitive players of online games on either PC or console, although many of them also play mobile games. This article focuses on the case of MTXs within online multiplayer games (either premium or free-to-play) on PC and console that can be considered optional buys, not pushed to the player by otherwise limiting the gameplay experience if they do not buy.

MTXs are part of the bigger media trend of hypermonetisation of loyalty programs (Lehdonvirta et al. 2009:1061). Loyalty programs are broadly adopted on multiple social media platforms to encourage further purchases and/or subscriptions and to distinguish between members based on their dedication to the product economy. However, in the context of games, the publisher's pursuit of alternative and/ or additional business models may collide with the moral economy of online gameplay, which has traditionally been guided by the ethics of fairness, skill, and the cultivation of play as craftsmanship (cf. Liboriussen 2013). Game ethics is most evident in the response to player actions of unethical substances, such as "deceiving, tricking, lying and generally being dishonest towards other players in the pursuit of game goals." (Carter 2015: 1).

When players adopt unethical methods towards other players in pursuit of game goals, the sense of unfairness arguably stems from players feeling their own project in the making is being sabotaged by other players who do not abide by the same rules of play. This type of "treacherous play" (Carter 2015), Carter argues does not necessarily reflect anti-social or immoral qualities (2015: 15). Instead, it might just be unusual player-vs-player tactics (ibid.). The digital artifacts of MTXs impose new structural limitations and opportunities for game participation on players, that similarly to 'treacherous play' demand players to renegotiate the existing ethics of play. As such, I ask the following question. How do players across platforms experience MTXs as a new economic model introduced in gameplay, and how do they react to it?

In the broader context, the digital game industry is in the forefront of commodification, where players are prompted to participate with their wallets at every stage of development as well as prior and after, either directly to the publisher or to third part corporations that deliver services (Sandqvist 2015: 16-17). For example, before the development phase, when players crowdsource games through Kickstarter.com, Indiegogo.com or early access funding models, such as Star Citizen (Cloud Imperium Games), Wasteland 2 (inXile Entertainment), and Ashes of Creation (Intrepid Studios). And, in early stage development when players can preorder games for exclusive extra content, during as well as after development phase, with downloadable content and game expansions, MTXs, monthly subscription services. And, recently, in regard to the cloud gaming and subscription streaming services such as Google Stadia and GeforceNow. As such MTXs take part of a bigger media trend of hyper monetisation of loyalty programs and gamification. Loyalty programs are broadly adopted on multiple social media platforms to encourage further purchases and/or subscriptions, and to distinguish between members depending on dedication to the product economy.

While this article adopts the notion of online games traditionally embracing the ethics of skill and fairness, it is necessary to acknowledge concerns regarding cyberbullying, misogyny, racism, as 
well as opaque and at times inefficient moderation and community management in online games. None of the above is of direct concern to the article's main premise, but I raise them anyway to avoid perpetuating a simplistic view of online games as purely egalitarian and meritocratic utopias, which they were not even before microtransactions came along. These concerns relate to the ethics of skill and fairness in that some players are denied the opportunity to compete at equal terms by a multitude of political interests from players, real-world global normativity, or corporations themselves.

For example, female players often experience group exclusion in massively multiplayer online role-playing games such as World of Warcraft (Blizzard) where group collaboration is crucial for progressing the game (Brehm 2013: 10). Continuing in the context of World of Warcraft, players playing the female dwarf character experience being "reviled by many players, systematically harassed, and unable to find anyone that will allow them to hunt in their groups" (Steinkuehler 2006: 208), due to the character's association with Chinese gold farmers. In the broader context of the digital game industry, the paradox of the assumption of play as a meritocracy, where skill and fairness rules, is even more problematic so. For example, as Higgin raises a number of issues about games and especially massive multiplayer online role-playing games being massively black-less fantasies that suffer from a history of "optic white environment" (2009: 22). This game environment has been maintained largely because minority groups have experienced a disadvantageous history and remain without technological accessibility and affordability, ultimately making games and play available only to the upper stratum of society (Higgin 2009: 22). In a similar vein, EVE Online (CCP Games) is considered a neoliberal simulator and its favouritism of players who are skilled navigators of the real-world neoliberal capitalism, who are rich career professionals, and live precariat lives which essentially make EVE a game for the elite (Johnson \& Mejia 2018: 5-7).
In the context of socioeconomic demands for participation in play, Mejia \& Bulut raise concerns how casual games, which are not premium but free-to-play or initially free, require later purchases to continue, offering a promise of release from everyday life but instead presenting additional demands for financial and social commitment to participate (2019: 166).

And more morally, companies are continuously trying to circumvent persistent toxic behaviours within gaming communities by educating players about and enforcing various codes of conduct, terms of use, as well as end-user license agreements, which are more likely to be serving corporate interests, such as avoiding legal liability, protecting assets and intellectual properties (Busch, Boudreau, Consalvo 2015: 185). Additionally, in League of Legends, Riot Games attempt to moderate toxic behaviour by implementing player jury duties in their Tribunal System where players can report other players that they feel have broken the code of conduct in terms of common decency. Busch, Boudreau, and Consalvo claim that many ambiguous jurisdictions are claimed in the name of decency, while little is championed for a clear Gamer's Bill of Rights that could clarify how players can play as opposed to maintaining uncertainty about how they ought not to play (ibid.). This literature matters significantly. For if we are to understand how players perceive the legitimacy and effects of micro-transactions on play then we need to understand how race, class, gender, and other features have already structured the normative moral economy of play.

In light of these developments, this article examines the ways in which casual online game players understand and adapt to the introduction of MTXs in everyday gameplay. I attempt "to understand the underlying motivation and logic that guide the media and culture industries, on the one hand, and the individual subjects who engage in media use, on the other hand" (Bolin 2012: 798). Through this study, the article contributes to the understanding 
of players' agency; that is, the capacity of individuals to act independently and to make their own free choices in digital games (Murray 1999), and the politics within the shifting economy of gameplay, where economic values and the search for new models of revenue by the online game industry threaten to overshadow and replace the moral values of play.

\section{FROM END-PRODUCT TO PERPETUAL COMMODIFICATION}

The game industry experienced an implosion and subsequent rebirth in the 1980s when games moved from arcades to homes in the form of hardcopy disks, and cartridges, which led to great corporate pressure on profitability that required game producers to constantly increase revenues to stay competitive (Deuze et al. 2007: 336). To circumvent this pressure, the gaming industry transitioned from relying predominantly on sales of software discs or cartridges to ongoing commodification of games; a perpetual cycle in which players are prompted to make continuous small sum investments in the game, either through downloadable content which is purchased, game extensions, monthly subscription fees, or MTXs, whether or not the base game is offered for free (Lizardi 2012: 37-40).

As such, MTXs take part in the bigger transition of monetisation strategies within the digital game industry. It can be argued that this strategy of perpetual commodification of games was inspired by earlier industry practices, such as arcade video games allowing users to temporarily borrow the game by inserting a coin into the machine to play until defeated or for a set amount of time. Or card collection games such as Magic: The Gathering where value and quality is artificially constructed based on rarity set by the publisher. However, I suggest that it is equally likely that the perpetual commodification strategy stems from close observation of players and player feedback to identify potential needs within the context of play. As an example, the market for trading virtual items for real money already existed between players before publishers adopting MTXs. In 1999, the predominantly multiplayer online (MMO) games Ultima Online (Origin Systems) and EverQuest (Verant Interactive \& 989 Studios) featured a multitude of virtual items that were difficult to obtain through gameplay, and these items were tradeable between players, who listed them on third-party consumer-to-consumer ecommerce websites, such as eBay (Hamari, Lehdonvirta 2010: 15). Therefore, the idea of trading virtual goods for real money may have been inspired by earlier player activities.

Turning this idea into a full-scale business strategy is not an original corporate invention. The practices of trading virtual goods for real money not only exist between leisure players but also between leisure players and player-workers. Player-workers are often perceived to have poor or no English communication skills, disrupting the play experience by advertising in the in-game chat, as well as preventing other players from utilizing the game environment as intended by developers due to their highly effective way of "harvesting" or "farming" its virtual resources (Liboriussen 2016: 317). These player-workers are either amateurs or employed to generate different types of valuable virtual content through otherwise repetitive and tedious gameplay and then to sell this content, for real money, to players (Nakamura 2009).

Before MTXs became the focus of discontent and heated debates, purchasing in-game content from player-workers were "widely considered the worst, more morally reprehensible form of cheating" (Nakamura 2009: 129). While the focus is particularly on the player-workers as "the other," it is not actually their personification but rather the service they provide and the players that make use of this service that are the source of frustration. As such, MTXs are a link in the chain of development in corporations attempting to adapt to a market characterised by continuously- changing user behaviours of virtual consumerism. 


\section{WHY PLAYERS BUY MICRO-TRANSACTIONS}

The notion that MTXs are part of a developmental play between developers and players has been referred to as the "bricolage where bits and pieces of media culture are creatively recombined or reflexively redeployed to produce something new" (Arvidsson, Sandvik 2007: 4). According to Arvidsson and Sandvik (ibid. 17), players' social participation in online games has commercial value, and players are thus codesigners or co-developers. When players started selling virtual items that they had acquired through gameplay to other players, they challenged the rules of play and introduced new means of virtual consumerism. Similarly, as mentioned previously, farmers took this new piece of media culture of virtual consumerism and redeployed it within their own context, where in-game advertising and real money trading is a natural part of the fantasy world (Liboriussen 2016: 320). These two events of bricolage are explicit examples of the value of player participation in online games, which provides new ways for publishers to adapt their monetisation strategies toward virtual consumerism.

According to Lehdonvirta et al., virtual consumerism is not distinct from material consumerism. The material lifecycle of consumption applies for virtual items as well, in the sense that someone is using up a particular resource, and thus there is a social lifecycle within a cultural economy of "momentary difference between haves and have-nots." (2019: 1074). In other words, players create preferences and "correct" modes of consumption that are motivated by the commodity's extrinsic attributes, such as the difficulty in obtaining it and its exclusivity as well as the possibility of association with individuals or groups (Lehdonvirta et al. 2009: 1073).

What drives this consumption in digital games, aside from social association and "haves" vs. "have-nots," is related to craftmanship. Liboriussen (2013) explains how playing digital games softens the opposition between play and work, as they can be played without external rewards as well as temporarily without a goal (Liboriussen 2013: 278). The otherwise binary opposition of work and play is problematised by Goggin's (2011) conception of "playbour" where attention is drawn towards "gold farmers' that are either willingly, or unwillingly, in their homes or in facilities (sometimes even prisons) playing games for the purpose of farming virtual content for the reasons of either earning a living, whether required to do so, or through free will (Goggin 2011: 365-366).

This blurred line between work and play in digital games arguably allows for a material consciousness as opposed to other types of games, such as board games, which present props for the player to uphold the simulation of a tactical process and for governing the rules of the game (Liboriussen 2013: 279). In board games these props do not change based on player interaction and cannot be moved skilfully in a sensory way, as opposed to digital games that can afford the player this sense of material consciousness and craftsmanship (ibid. 279). According to Liboriussen (2013: 280, 281), craftmanship in games entails projective identity, a project in making, competition, and peer-to-peer teaching as well as the loss of self in a temporal suspension of goal-directedness. In other words, players are building objects through sensory input while utilising, for example, a keyboard and mouse or gamepad. These objects are projects that reflect the player's values and desires, which are often compared with other players' projects in a battle of quality, and together these projects lead to a temporary suspension of the goal in favour of "creative engagement with the material at hand" (ibid. 280, 281).

The previous research on player engagement with gameplay and virtual commodities has focused extensively on describing the motivation for interacting with these elements of play (Guo \& Barnes 2007; Lehdonvirta, et al. 2009; Lehdonvirta 2009) without exploring the reasons why users may oppose or avoid them - beyond 
identifying the objects' social lifecycles (Hamari, Lehdonvirta 2010).

\section{THEORETICAL FRAMEWORK}

Whereas all economies are moral in the sense that they are guided by predominant rationality, what is considered moral and immoral can vary within contexts. The moral economy of online gameplay has traditionally been guided by the ethics of fairness, skill, and the cultivation of play as craftsmanship (cf. Liboriussen 2013). With MTXs, these norms are put under pressure, a common tension between economic and ethical valuations (Sayer 2004).

Drawing on Adam Smith's work, The Theory of Moral Sentiments (1759), and his conception that "individuals are social beings who are always dependent on others and concerned with understanding them; benevolence and a need for recognition, as well as self-interest, are normal, 'natural' dispositions," (Sayer, 2003: 341). Sayer challenges the modern neo-liberalist conception of "capitalism as a form of economic organisation in which responsibilities to others are instantly discharged and cleared with the simple exchange of goods for money." (2004: 11). He argues that the motivation for economic action is much more nuanced than the pursuit of self-interest. More specifically, Sayer (2003: 342) focuses on the social-material relations that are embedded in commodity consumption, which can be between consumer-producer, consumer-purchaser, or consumerconsumer2.

Due to these opaque relationships; rights, entitlements, responsibilities, and appropriate behaviours play a significant role in individuals' engagement in economic actions (Sayer 2004: 3). Needless to say, "morality" is a contested term as it is often disregarded as disguised egoism that is either "idealistic or conservative, ignoring or concealing power" (Sayer 2000: 4). On the one hand, Sayer opposes this belief

For example, joint consumers or third parties directly or indirectly affected by the act of consumption. In other words, another consumer might feel entitled to the same resource. that analysis of the moral economy is illsuited to account for the political economy of power and domination, as power is often dependent on individual's moral commitment (ibid.), such as digital game publishers' reliance on players' moral concern for cheating and software piracy and in turn, their likeliness of embracing "alwayson" digital rights management tools as a norm in the industry to combat it. On the other hand, he admits that the analysis of a moral economy is not a simple task, as morals "are often complex and involve intractable dilemmas, but that does not negate their moral character." (Sayer 2000: 4).

For some players' morals, norms, and values are structured in ways that make it easier to play and more difficult for others, as I have shown in the introduction by taking an example in female players experience group exclusion, or players playing certain characters being harassed for the association to farmers. More generally, power and dominance in digital gaming culture is central to the question 'are we playing together?' as players with different motivations (Vossen 2018: 210). These different motivations cause different moral economies or orientations of subversive and deviant play, as in an example Vossen provides where trash talk is increasingly becoming the norm within digital games and taking offense to racist and sexist insults is considered deviant behaviour (ibid. 215). In other words, we need to understand how race, class, gender, and other identifying features have already structured the normative moral economy of play.

Accordingly, Sayer (2007) defines the "moral economy" as the influence that moral orientations and norms of rights, entitlements, responsibilities, and appropriate behaviours have upon economic activities. Meanwhile, these morals and norms also risk becoming "reinforced, compromised or overridden by economic pressures" (Sayer 2007: 262).

In this context, players can resort to different everyday tactics of agentic action (de Certeau 2011) within contexts of play 
to reinstall, object to, or negotiate this pressure. De Certeau's (2011) concept of tactics insinuates that, while agency may be granted by games, players will claim and use agency in ways that were not intended by the developers.

De Certeau (2011) views consumption and production as synonymous with tactics and strategies, respectively. Consumption is another type of production, in that the users can formulate multiple different and unintended ways to utilize the product (2011: xii, xiii). These alternative utilizations are what de Certeau considers to exemplify user tactics toward the production strategies or, in other words, the intended use-cases. De Certeau perceives strategies as "a place that can be delimited as its own and serve as the base from which relations with an exteriority composed of targets or threats [...] can be managed" (ibid. 35). Meanwhile, tactics are "calculated action[s] determined by the absence of a proper locus" (ibid. 37). With these tactics and strategies, consumerism changes the power relationship between consumers and producers, where the distinction between them lies in how the strategies are visible and mappable to the user, while tactics are invisible to the producer because they are "clever tricks of the 'weak' within the order established by the 'strong,' an art of putting one over on the adversary on his own turf, hunter's tricks, manoeuvrable" (ibid. 40).

\section{METHOD}

In order to analyse the moral economy of MTXs on the side of the players as well as their everyday tactics, I adopted a multimethod approach combining three focus groups, one interview, and one podcast interview. In total, the interviews consisted of six Swedish and two Danish informants, and the podcast interview consisted of three Danish informants. To elicit player tactics in the moral economy of MTXs, a qualitative approach helped me to grasp multiple meanings and experiences from the interviews (Markham, Baym 2009).

This study collected data through one in-person interview (informant A) and one in-person focus group, consisting of three informants (Informant B, C, D), as well as two online focus groups, consisting of two informants in each (Informant E, F, $G, H$ ), which were conducted using Skype with voice-recording software. In addition, data were collected through a podcast interview. The interview questions were sent to the podcast hosts, who would then discuss them in the following podcast episode. All interviews were later transcribed. All the audio material was collected in April 2018, with focus groups and podcast interview lasting about 60 minutes and the interview 30 minutes. The focus group informants were reached through chain sampling, with one informant of each group being a selected personal acquaintance and the rest of the informants of each group being within that acquaintance's social network. I contacted the informant for the individual interview, who was selected from among my acquaintances based on the realisation that I had not been able to reach any female informants. This led me to forfeit my initial principle of chain-sampling. Additionally, some of the informants were game developers with ties to game developing corporations and, as such, their non-disclosure agreements required complete anonymity of all informants.

Alongside the additional interview to add a female informant to the sample, I decided to add the podcast interview to the empirical material as I have been a frequent listener of the podcast, and the hosts tend to go beyond discussing Destiny 2 (Bungie), which their podcast is about, to discuss the industry as a whole. The hosts represent well-informed and avid players who stay on top of industry news and, as such, their debates often pivot around current industry trends and its impact on their gaming experience. For this reason, I was intrigued to add their voice in this sample. After receiving the podcast recording, I discovered that the podcast hosts had followed the interview protocol as if it was a part of their own manuscript, so all questions were discussed. 
In terms of limitations, the informants were reached through chain-sampling starting with my acquaintances, meaning one informant per focus group is within close proximity of my social network. Since all informants except two were 20 to 30 year-old white males, had been or were in higher education at the time, were from Sweden or Denmark, and primarily play online competitive multiplayer games on either PC or console, this sample of informants represent a player base that are white male adults who can afford expensive hardware and primarily play massively multiplayer online roleplaying games, massively multiplayer online, multiplayer online battle arena, and first-person shooter games (for details please see the appendix). As such, the sample does not intend to be representative of all online players' attitudes towards MTXs. However, it provides insights into how some players formalize different tactics based on different experiences of the moral economy of MTXs. Furthermore, as Deuze et al. (2007: 348) have established, there are multiple social and demographic differences between players, which complicates the assumption that socio-economic segmentation will suffice for establishing representation. To identify the player types of my informants, I initiated all interviews by asking them which hardware (console, mobile, PC) they use, what games they play, and what types of MTXs they have encountered in gameplay (for details please see the appendix).

The data were analysed using Braun and Clarke's (2006) six-step thematic coding process. Accordingly, I (1) familiarised myself with the data during the process of transcribing; (2) generated initial codes and discovered themes or patterns in the material using the NVivo software tool; (3) arranged the different codes and started working out the relationships between them and the themes that had emerged from step 3; (4) reviewed the themes to determine whether enough data existed to support them; (5) defined and named the final themes to adequately communicate their nature; (6) reported the findings by conducting data analysis, followed by moving beyond the description of the data by incorporating the theoretical framework of the moral economy and de Certeau's conception of tactics.

From the thematic coding process, I distinguished four different MTXs characteristics between the themes that provoke different moral problems for the players and three different types of tactics towards MTXs that players employ in relation to their understanding of gameplay as a moral and community practice. The MTXs characteristics are purely cosmetic versus changing the rules of play, obtainable through gameplay and random reward; while the types of tactics are avoidance and sporadic activism, compliance within limits, and embrace MTXs for purposes other than those intended.

\section{THE MORAL ECONOMY AND GAME PLAY}

Lehdonvirta et al. (2019) conclude that the main drivers of virtual consumerism are the social associations of "haves" and "havenots," the extrinsic attributes of being difficult to obtain, and exclusivity in group association, all of which together constitute the social lifecycle in a cultural economy (1074). My sample confirms these observations, as informants frequently mention these drivers when talking about MTXs, as in informant A's statement:

$$
\begin{aligned}
& \text {... in Wow [World of Warcraft] } \\
& \text { when you see someone on the } \\
& \text { purchasable mounts everyone } \\
& \text { knows "oh, he paid } 10 \text { euro for } \\
& \text { that mount" and nobody cares. } \\
& \text { In another game, you do not } \\
& \text { know if he is a super professional } \\
& \text { player or if he bought himself (sic) } \\
& \text { that item. (Informant A) }
\end{aligned}
$$

This distinction between goods purchased through MTXs and items obtained through challenging gameplay is important to the user, as the virtual goods represent achievements and communicate a certain skill level to other users if they are obtained 
through gameplay. Meanwhile, items that are purchased using MTXs do not share this socially perceived value. To the player, there is a certain amount of pride and prestige tied to items obtained through gameplay. However, items purchased using MTXs also have a cosmetic value to the players according to Informant $F$, who distinguishes between MTXs in single and multiplayer games:

It [MTXs] makes no sense in single-player games, since you are the only one that can see these cosmetics. And, the point is after all to show yourself to others, and be admired, and the whole social aspect does not exist in singleplayer games.

Hence, cosmetic items bought using MTXs have a value to some players in the multiplayer context, as it allows them to show others their visual taste. This is in line with Liboriussen's (2013: 280, 281) craftmanship in digital games as creative engagement and loss of goal-directedness in a projective identity. This distinction between cosmetic items purchased with MTXs and items obtained through challenging gameplay, representing taste and player skill level respectively, is important to players for prestige, but they both hold social value for being able to communicate personal attributes.

According to Informant D, when MTXs change the rules of the game, they can have direct or indirect effects upon players and the player communities:

I guess fragmentation occurs for those who do not have the cards to rank up higher, in that case [Heartstone]. In other games, like Call of Duty, you have to buy separate expansions to be able to play certain maps, and that's definitely fragmentation.

(Informant D)
The impact on the wider player base is perceived to cause fragmentation between "haves" and "have-nots" since the level of participation is dictated by MTXs, which, in turn, determine the user's ability to compete. As a result, the financial commitment and socio-economic background determines whether users can participate in the full product and compete at the same level as everyone else.

The podcast host Mika questions financial commitment as the primary determiner of "haves" and "have-nots." According to him, players can falsely appear as users of MTXs, which blurs the lines between who make uses of MTXs and who does not:

That we [the podcast hosts] do not have this desire [to purchase MTXs], I think has a lot to do with that we have played Destiny 2 a lot, and actually do not need that many items. I think it would be interesting to hear it from one that has just gotten into the game if he/she looks at us and thinks "wow they have spent a lot of money on micro-transactions".

Mika portrays the different levels of association as heavily tied to MTXs. In Destiny 2 (Bungie), players can obtain items which are otherwise purchased through MTXs by completing time-consuming, in-game activities. Mika insinuates that this distinction - between having obtained MTX items through in-game activities or having purchased them with real currencies - is almost impossible for other players to determine. As a result, on the one hand, frequent players risk becoming associated with players that purchase items through MTXs; on the other hand, items obtainable through MTXs become a symbol of avid players and high skill level as they communicate a certain level of player experience to other players.

Morten disagrees with Mika, as he does not consider it likely that MTXs represent anything significant worthy of social association: 
I do not think groups are created in the community as a result of micro-transactions. If you have received ornaments, you have been lucky with RNG [Random Number Generation], which makes you stand out in game play from other players.

Instead Morten does not consider MTXs to have the social value to formulate legitimate groups that players would want to be associated with, as it is not skill or craftmanship but rather a coincidence or luck that makes the player stand out. Arguably, the case of the loot box MTX is problematic to the ethics of play, as the extrinsic attributes of the item are forfeit the moment it is rewarded randomly instead of being obtained through a challenging task or carefully selected by the player to represent his or her taste. When luck determines "who should do, get or control what" (Sayer 2017: 23) it nulls the moral economy of play.

The disdain toward the potential capability of MTXs to represent player skill and achievements is arguably related to a moral orientation toward the rules of play, and Morten's argument suggests that these morals are being put under pressure because MTXs blur the lines between what visual items adequately represent players' skills and craftsmanship.

Furthermore, when items purchased with MTXs change the rules of play by allowing players to gain an advantage over other players, it provokes reactions from players, as expressed by Informant D:

It gets a little annoying if it becomes a huge part requiring you to buy, because then people with economic capital becomes the "winners" of the game. But, I have not experienced this to be so severe as, for example, Battlefront 2. And if the games would go that direction, I would just stop playing. (Informant D)
Informant $D$ emphasizes the discriminatory factor of players with socio-economic advantages being able to gain an upper hand and how this infringes on the moral rules of fairness in games. Battlefront 2 (Electronic Arts) is called out as an example of MTXs allowing individuals to gain an advantage, which led Informant D to formulate a tactic constituting a threshold and a point of reference to quickly determine whether a game is crossing the ethical lines of fairness in gameplay. This is what de Certeau regards as tactics being unmappable and "scattered over areas defined and occupied by systems of "production"" (de Certeau 2011: xii). As opposed to tactics, these systems constitute the visible strategies, and allows the user to quickly assess the strategies at hand and then to formulate relevant tactics.

In sum, players' perceptions of MTXs vary depending on their nature and the informants distinguish between MTXs based on three levels where agency is maintained or limited as purely cosmetic versus changing the rules of play, obtainable through gameplay, or random reward, which guides their reasoning. With each characteristic, different moral problems arise for the informants. For example, MTXs that are purely cosmetic afford players the opportunity to communicate their taste, prestige, and accomplishments by not interfering with virtual goods obtained through gameplay; whereas, MTXs that change the rules of play degenerate the sense of pride and prestige tied to items obtained through challenging gameplay, as competition is no longer on equal terms, although they are somewhat morally justified as long as it is clearly visible whether or not a player makes use of MTXs.

First, the most basic distinction of MTXs that players draw - the agency to communicate skill level, prestige, accomplishments, and taste - clearly remains, as well as the ability to socially distinguish between players who are dedicated and skilled and those who purchase MTXs. Second, in the context of MTXs being obtainable through gameplay, this agency 
and social association are removed as the distinction becomes blurred. Finally, when MTXs are turned into random rewards, whether they are purchased or obtained through gameplay, the agency to communicate is removed completely, as items only communicate fortune or misfortune, which effectively removes the extrinsic attributes of virtual items.

However, this is not different from non-MTX randomized items in games, which have existed for decades. In many games, particularly RPGs, finding a rare and expensive item is always to some extent subject to chance, which is equally controversial. However, these items tend to be exclusively random. The problem arise when items, whether non-MTX or MTX, are obtainable through specific game-related tasks with which they can later be associated, while also obtainable through any type of gameplay activity or purchase.

Within this common tension between economic and ethical valuations, players resort to different everyday tactics of agentic action (de Certeau 2011) within contexts of play to reinstall, object to, or negotiate this pressure. De Certeau's (2011) concept of tactics insinuates that agency may be granted by games, but players will claim and use it in ways that were not intended by the developers. These player tactics toward MTXs include avoidance and sporadic activism, compliance within limits, and utilizing MTXs for purposes other than those originally intended.

\section{PLAYER TACTICS TOWARD MICRO-TRANSACTIONS}

Avoidance and sporadic activism reflect negative reactions and contempt toward the implementation of MTXs within games. The players adopting this tactic tend to have identified the antagonist(s), [often the publishers] and are determined in their means of confrontation or avoidance.

Informant $\mathrm{G}$ explains certain reactions out of frustration toward MTXs: "I read a lot about it, sometimes I also participate in the debate by putting up a post. (...) because I feel that the companies are exploiting me as a consumer."

This exploitation was elaborated upon earlier in the interview:
In Destiny they have changed loot boxes, and it makes no sense. I think the most cosmetics should not be in loot boxes but instead be a part of the content as an incentive for playing the game.

This sense of exploitation has led Informant $G$ to resort to confrontation by expressing frustration through social media. This tactic is arguably a case of media bricolage where the user recombines and redeploys the media experience (Arvidsson, Sandvik 2007: 4). Meaning, the player's experience of the game is collected and redeployed into a social media culture of activism, where the publisher loses control of the portrayal of the game. For the publisher, this means that the place in "which relations with an exteriority composed of targets or threats" (Certeau 2011: 35, 36) cannot be delimited as its own anymore when exclusive control over public relations is lost.

The publishers' declining control over relations with an exteriority, as a result of users' media activism, arguably causes a paradigm shift when the publishers announce in advance of a game's release whether or not it will include MTXs. Informant A discusses this:
It has become a selling point; one year in advance developers announce that their upcoming game will not have micro-trans- actions. And, everybody seems to think that will determine if it is a good game.

The paradigm shift is the change from producers deploying strategies toward users adopting tactics. In this case, it is the producers that must adopt measures of deception and transform their strategies into tactics to manoeuvre and appeal to consumer desires (de Certeau 2011: 37). 
Some players formulate less active tactics, such as informant A's avoidance strategy toward games with specific MTX strategies:

I do not mind playing the game one hour a day, but to keep up with in-game currency I had to play 10 times that to keep up, so I quit. Games with the same model I will not even touch now. So, it definitely has influenced my purchase decisions, that I now avoid games with this approach.

Informant A has mastered the surroundings of the game and is confident in identifying and assessing the revenue strategies that publishers adopt. While not as active as the redeployment of bricolage in social media, it remains active in the sense of "hunter's tricks, manoeuvrable" (Certeau 2011: 40) as in, not being compliant and accepting the terms but instead developing an action plan for how to avoid the MTXs. Other avoidance tactics are motivated by a pure socio-economic standpoint, as Informant $\mathrm{H}$ expresses. "[I] never felt like buying [MTXs] because the game is already very expensive. [...] Mass Effect costs 700 [SEK], so that makes me not want to spend any more." The informant does not bring up any examples where he or she feels wronged by the publisher or game; instead, the developed tactic comes from an economic perspective of it being unfeasible to spend more money on this particular game.

While some tactics are based on activism and revolt against corporate strategies of exploitation, others approach it with caution and develop principles and preconditions for why they should allow MTXs within their everyday use of digital games. Compliance within limits is based on flexibility and acceptance of MTXs, although adopting workarounds or compromises. The players adopting this tactic embrace MTXs based on the premise that they are not forced to purchase them to enjoy the game or because the MTX strategy complies with principles such as being purely cosmetic and allowing the player to work toward MTXs through gameplay. Informant A describes a principle of minimum criteria:

I make my purchase calls based on if I think the minimum reward, in terms of materials or ingame currency recovered from destroyed un-wanted items. Not all games have this mechanism.

Informant A's principle of MTXs having a minimum reward that secures progress towards something is what Liboriussen (2013: 277) terms the craftsman's need to anticipate what comes next as well as being one step ahead of the materials at the player's disposal.

In other cases, the condition for accepting MTXs as an integrated part of the game experience is exclusively based on the moral distinction between whether items are purely cosmetic or change the rules of play, as identified previously. This is for example the case of Informant E:

If the games are pay-to-win, then I think it's completely terrible. But I don't have a problem with games having micro-transactions in them, if it is just cosmetics, as that actually boosts the experience of playing.

Informant E is willing to accept MTXs as an integrated part of the game experience as long as they do not interfere with the competitive aspect of the game experience. If the strategies comply and MTXs are only cosmetic additions, they are believed to actually enhance the game experience. The dichotomy of MTXs that are cosmetic vs. changing rules of play resonates through most of the informants' accounts, although it is continuously dependent on additional contextualisation. Informant B exemplifies this changing reasoning:

If it is a free-to-play game, you will have a higher tolerance for having things that require money. 
You sort of expect to have to pay. But, if it is a full price game for 60 euros and then they have microtransactions being the main thing that drags the game, that's very frustrating...

As such, MTX is not a commercial phenomenon that players have a generic opinion or attitude about; rather, it is constantly shifting depending on the context, such as the hardware (mobile, $\mathrm{PC}$, or Console) and genre of the game. This arguably adds to the complexity of corporations identifying and mapping user tactics, which are "scattered over areas defined and occupied by systems of "production"” (de Certeau 2011:xii).

Compared to other tactics that reflect contempt or caution towards MTXs, some players perceive them as an opportunity to express their economic commitment in hopes of being acknowledged by other players for it. MTXs can be embraced for alternative purposes, resulting in enthusiasm and opportunism toward MTXs through the pursuit of additional pleasures from gameplay, as informant C observes here.

Yeah, I think that is because people want to be part of a community, more than they did before. People today play less games and more of the same game, and when they do that, they want to be a part of that community, in turn wanting more of the game.

Informant $\mathrm{C}$ takes an example from other players' tactics rather than his or her own. Nevertheless, financial commitment to cultural objects has been a part of the digital games industry for a long time before MTXs was established, with strategies such as preordering, various levels of special premium editions, expansions, and merchandise. When players utilize MTXs to signify their commitment to the game for other players to see, it reaches beyond MTXs as a commercial object to be purchased and consumed, that simulates the real-world cultural economy of "momentary difference between haves and have-nots" (Lehdonvirta et al. 2019: 1074). Instead the financial commitment becomes more than just a tactic of association and dissociation; it also involves showing commitment to a cultural object for others to see, similar to much earlier practices of art patronage, whereby wealthy nobility would protect and support artists and "preserve their artwork for posterity" (Davies, Sigthorsson 2013: 25).

While this analysis illustrates varied responses and reactions towards the digital game industry's current monetization practices, most responses insinuate a moral orientation that these monetisation strategies are fundamentally wrong to the moral economy of play, which is traditionally guided by the ethics of fairness, skill, and the cultivation of play as craftmanship. Guided by this orientation, the players produce different tactics to deal with, cope, or avoid these monetisation strategies, such as airing their opinion through other mediums, complete avoidance, spatial avoidance, or by establishing personal minimum criteria for how games should handle MTXs. However, what is considered moral and immoral varies within contexts. On the one hand, players condemn corporations for taking advantage of the competition that exists between players by diminishing the value of prestige and accomplishments. On the other hand, the desire to be associated with skill and accomplishment is so important to players that some of them are willing to pay large amounts of in-game currencies, as Informant A states.

... It was very common for the bigger guilds [formal association of players] to charge for one to come on their raids [challenging content that require multiple players to collaborate for success], and if a suitable item dropped, that player could have it. 
Players purchasing player services to obtain items as well as to offer these services, as informant A describes, is a tactic that shares characteristics with the tactic of player-workers, who play the game to obtain and sell valuable content to players for real currencies (Liboriussen 2016: 317). Within this context, this tactic is somewhat socially accepted by players in comparison to MTXs, as it arguably represents the player's skill level in the economy game while also being a way to manoeuvre gameplay constraints. This suggests that these player reactions toward corporations are due to a sense of a broken "social or moral contract." Online games have their own socio-economic system, and the introduction of MTXs effectively makes the naturally-generated inequalities meaningless, and the realworld socio-economic system invades that of the online game.

When player-workers first introduced the concept of MTXs as player-player services, the preconditions of the economy game in most online games were disrupted due to this "unnatural" way of obtaining and purchasing virtual goods. For a time, corporations acted against these playermade MTX systems because they disrupted the economy game. However, they later introduced the same MTX system, only this time as a publisher-player service, thus attempting to maintain two parallel moral economic functions (Sayer 2007: 265), wherein the player is forced to obey two separate rulesets for systems that conflict with each other - the economy game between players and MTXs with publishers. Sayer identifies this tendency:

Although economic actors may, particularly where economic incentives and pressures allow or encourage it, behave in ways which are anti-social, economic institutions and practices generally rely heavily upon actors' propriety, in at least not cheating or deceiving others. (2007: 265)
Paradoxically, these two systems interfere with each other, where dedication to either is perceived as inappropriate by players or publishers. MTXs are generally disregarded by players as an inappropriate approach to obtaining status, as they do not reflect skill and experience. Further, player-player and player-worker services are at times viewed as inappropriate or dishonest business practices compared to MTXs. However, where MTXs distort the means of establishing even grounds for competition, playerplayer and player-worker services remind players that publishers are not the only distributor, and can be accepted as representative of skill in the economy game.

\section{CONCLUSION}

MTXs offer shortcuts to obtaining rewards and status in gameplay. However, the speed and lack of skill required for acquiring items through MTXs can be perceived by players as incompatible with the moral economy of play. Paradoxically, while MTXs are viewed by some players as fragmenting the community and undermining game values, for other players they have a precisely opposite meaning, promising to bring more social value to playing communities that have experienced the need to commit economically for a long time. Furthermore, players can often find MTXs to be rewarding in terms of enhancing the aesthetics of play and status.

The analysis shows that players perceive virtual items and goods obtained through in-game activities or MTXs as a means to communicate their skill level, taste, and experience as a fundamental part of the moral economy of establishing fair grounds for competition. In relation to MTXs, they distinguish among three levels in which agency is maintained or limited; purely cosmetic versus changing the rules of play, obtainable through gameplay, and offering a random reward. The informants repeatedly indicate their frustration related to MTXs, distorting the agency of communicating player experience or skill level and focusing instead on the size of one's wallet. As such, the moral economy of play is compromised the moment the MTXs begin 
to distort the visual representations of skill and experience that otherwise determine even grounds for competition.

Altogether, these findings show that digital game companies are trying to adapt their economic models to extract ever more private value from gameplay by experimenting with a multitude of business models that relies on user activities. Whereas the discussion shows how players negotiate these models of commodification in terms agency limitation in ambivalent ways, through everyday tactics of both resisting and embracing economic values in the moral economy of play. Furthermore, due to this negotiation, players are generally concerned about the invasive nature of economic values taking priority over the values that guide the practices of play, as they have a moral concern regarding how norms and values in play are compromised or overridden by outside economic pressures. Discovering players' perception of the legitimacy and effects of microtransactions on gameplay is significant for understanding consumption and commodification within the rules of play. As digital game publishers are increasingly relying on the perpetual cycle of commodification, they are also becoming increasingly reliant on MTXs as an accepted norm within the moral economy of play. To this end it is crucial to understand what types of MTXs compromise or override the moral economy that guides play between players.

Having established that MTXs compromise or override the moral economy of play, a next step would be to look at how MTXs are being normalized within the context of play. By disregarding that some players oppose MTXs, and instead look at players that embrace it, we can get an idea of whether and how it is being integrated into the dominating political economy of play. This sample is focused on adults between ages 20 to 30, who represent the generation that experienced the digital game industry transitioning from end-product creation to perpetual commodification. A younger audience may have a significantly different perspective on MTXs.

\section{REFERENCES}

Arvidsson, Adam; Sandvik, Kjetil. 2007. 'Gameplay as Design: Uses of Computer Players Immaterial Labour'. - Northern Lights: Film and Media Studies Yearbook 5, 1, 89-104.

Baym, Nancy. K.; Markham, Anette. N. 2009. Internet Inquiry: Conversations about Method. Los Angeles:

Sage Publications.

Bolin, Göran. 2012. 'The Labour Of Media Use'. Information, Communication \& Society 15, 6, 796-814. Braun, Virginia; Clarke, Victoria. 2006. 'Using thematic analysis in psychology'. Qualitative Research in Psychology, 3, 2, 77-101.

Brehm, Audrey. L. 2013. 'Navigating the feminine in massively multiplayer online games: gender in World of Warcraft'. Frontiers in Psychology, 4, 903.

Busch, Thorsten; Boudreau, Kelly; Consalvo, Mia. 2015. 'Toxic gamer culture, corporate regulation, and standards of behaviour among players of online games'. In S. Conway and J. deWinter (eds.). Video Game Policy: Production, Distribution, and Consumption, 176-190.

New York: Routledge.

Carter, Marcus. 2015. 'Massively multiplayer dark play: Treacherous play in EVE Online'. In . E. Mortensen, J. Linderoth, \& A. M. L. Brown (eds.). The Dark Side of Game Play: Controversial Issues in Playful Environments. New York: Routledge.

Castronova, Edward. 2006. 'Virtual Worlds: A Firsthand Account of Market and Society on the Cyberian Frontier'. - K. Salen, E. Zimmerman (eds.), The Game Design Reader: A Rules of Play Anthology. Cambridge, MA: MIT Press, 814-863.

Davies, Rosamund; Sigthorsson, Gauti. 2013.

Introducing the Creative Industries: From Theory to Practice. London: SAGE.

De Certeau, Michel. 2011. Practice of Everyday Life. University of California Press.

Deuze, Mark; Martin, Chase Bowen; Allen, Christian. 2007. 'The Professional Identity of Gameworkers'. -

Convergence: The International Journal of Research into New Media Technologies 13, 4, 335-353.

Guo, Yue; Barnes, Suart. 2007. 'Why people buy virtual items in virtual worlds with real money. ACM SIGMIS Database: The DATABASE for Advances in Information Systems, 38, 4, 69-76.

Goggin, Joyce. 2011. 'Playbour, farming and labour'. Ephemera 11, 4, 357-368.

GREF 2019. 'Update - Blurring of Lines Between Gambling and Gaming'. http://www.gref.net/updateblurring-of-lines-between-gambling-and-gaming/ (2 October 2019).

Hamari, Juho; Lehdonvirta, Vili. 2010. 'Game Design as Marketing: How Game Mechanics Create Demand for Virtual Goods' - International Journal of Business Science \& Applied Management 5, 1, 14-29.

Higgin, Tanner. 2008. 'Blackless Fantasy: The Disappearance of Race in Massively Multiplayer Online Role-Playing Games'. Games and Culture, 4, 1, 3-26. Johnson, Mark Richard; Mejia, Robert. 2018. 'Making Science Fiction Real: Neoliberalism, Real-Life and Esports in Eve Online.' Journal of Virtual Worlds Research 10, 3, 1-13.

Knaus, Christopher. 2017. 'Gambling Regulators to Investigate "Loot Boxes" in Video Games'. https://www.theguardian.com/games/2017/nov/24/ gambling-regulators-to-investigate-loot-boxes-invideo-games (24 November 2017).

Lehdonvirta, Vili. 2009. 'Virtual item sales as a revenue model: Identifying attributes that drive purchase decisions'. Electronic Commerce Research, 9, 1-2, 97-113.

Lehdonvirta, Vili; Wilska, Terhi-Anna; Johnson, Mikael. 2009. 'Virtual Consumerism'. - Information, Communication \& Society 12, 7, 1059-1079. 
Liboriussen, Bjarke. 2013. 'Craft, Creativity, Computer Games: The Fusion of Play and Material Consciousness'. - Philosophy \& Technology 26, 3, 273-282.

Liboriussen, Bjarke. 2016. 'Amateur Gold Farming in China: "Chinese Ingenuity," Independence, and Critique. Games and Culture, 11, 3, 316-331. Liboriussen, Bjarke. 2016. 'Amateur Gold Farming in China". - Games and Culture 11, 3, 316-331.

Lizardi, Ryan. 2012. 'DLC: Perpetual Commodification of the Video Game'. Democratic Communiqué, 25, 1, 33-45. Mejia, Robert; Bulut, Ergin. 2019. 'The Cruel Optimism of Casual Games: Neocolonialism, Neoliberalism, and the Valorization of Play'. Critical Studies in Media Communication 36, 2, 156-70.

Murray, Janet. H. 1999. Hamlet on the Holodeck: The Future of Narrative in Cyberspace. Cambridge, MA: MIT Press.

Nakamura, Lisa. 2009. 'Don't Hate the Player, Hate the Game: The Racialization of Labor in World of Warcraft'. Critical Studies in Media Communication, 26, 2, 128144.

Sandqvist, Ulf. 2015. 'The Games They are a Changin': New Business Models and Transformation Within the Video Game Industry'. Humanities and Social Sciences: Latvia, 23, 2, 4-20. doi:10.22364/hssl

Sayer, Andrew. 2000. 'Moral Economy and Political Economy'. Studies in Political Economy, 61, 1, 79-103. Sayer, Andrew. 2003. '(De)Commodification, Consumer Culture, and Moral Economy'. - Environment and Planning D: Society and Space 21, 3, 341-357.

Sayer, Andrew. 2004. 'Moral Economy'. Lancaster: Department of Sociology, Lancaster University. http://www.lancaster.ac.uk/sociology/research/ publications/papers/sayer-moral-economy.pdf. Sayer, Andrew. 2007. 'Moral Economy as Critique'. New Political Economy 12, 2, 261-270.

Steinkuehler, Constance. 2006. 'The mangle of play'. Games and Culture, 1, 3, 199-213.

Tomić, Nenad. 2018. 'Economic Model of Microtransactions in Video Games'. - Journal of Economic Science Research 1, 1, 17-23.

Vossen, Emma. 2018. 'The Magic Circle and Consent in Gaming Practices'. - K.L. Gray, G. Voorhees and E. Vossen (eds), Feminism in Play, New York: Palgrave MacMillan, 205-220.

\section{APPENDIX}

Individual Interview

Informant A

Gender: Female

Nationality: Swedish

Games: Candy Crush, Mass Effect and Hitman

Platform: PS and Mobile Phone

MTX Encounters: Pop-ups and Fun Pain

Conducted: April 28, 2018

Focus Group Interview 1 - Offline

Informant B

Gender: Male

Nationality: Swedish

Games: World of Warcraft, For Honor, Diablo 3

Platform: PS and Mobile Phone

MTX Encounters: Loot Boxes, In-game Currency,

Upon Login

Conducted: April 15, 2018

Informant C

Gender: Male

Nationality: Swedish

Games: World of Warcraft, Overwatch, Clash of Clans Platform: PC and Mobile Phone

MTX Encounters: Loot Boxes, In-game Currency,

Pop-ups, Upon Login

Conducted: April 15, 2018

Informant D

Gender: Male

Nationality: Swedish

Games: World of Warcraft, Overwatch, Counter-Strike Platform: PC and PS

MTX Encounters: Loot Boxes, In-game Currency, Upon Login

Conducted: April 15, 2018

Focus Group Interview 2 - Online

Informant E

Gender: Male

Nationality: Danish

Games: Halo, Division, Assassins Creed, Destiny

Platform: PS and Xbox

MTX Encounters: Loot Boxes, In-game Currency, Upon Login

Conducted: April 23, 2018

Informant $F$

Gender: Male

Nationality: Danish

Games: Battlefield, Assassins Creed, Destiny

Platform: PS and PC

MTX Encounters: Loot Boxes, In-game Currency,

Upon Login

Conducted: April 23, 2018

Focus Group Interview 3 - Online

Informant $G$

Gender: Male

Nationality: Swedish

Games: Hearthstone, FIFA, Call of Duty, Fortnite

Platform: PS and Mobile Phone

MTX Encounters: RMM, Loot Boxes

Conducted: April 22, 2018

Informant $\mathrm{H}$

Nationality: Swedish

Gender: Male

Games: Hearthstone

Platform: PC and Mobile phone 
MTX Encounters: RMM

Conducted: April 22, 2018

\section{Podcast}

Informant Morten, Nikolaj \& Mika

Gender: Male

Nationality: Danish

Games: Destiny 2

Platform: PS

MTX Encounters: Bright Engram - Equivalent to Loot Boxes

Conducted: April 11, 2018 